\title{
Combating COVID-19 Pandemic in Bangladesh: A Memorandum from Developing Country
}

COVID-19 in Bangladesh

Abu Tayab Moin ${ }^{1}$, Mohammad Najmul Sakib ${ }^{1}$, Yusha Araf $^{2}$, Bishajit Sarkar $^{3}$, Md. Asad Ullah ${ }^{3 *}$

${ }^{1}$ Department of Genetic Engineering and Biotechnology, Faculty of Biological Sciences University of Chittagong, Chattogram, Bangladesh

${ }^{2}$ Department of Genetic Engineering and Biotechnology, School of Life Sciences, Shahjalal University of Science and Technology, Sylhet, Bangladesh

${ }^{3}$ Department of Biotechnology and Genetic Engineering, Faculty of Biological Sciences, Jahangirnagar University, Dhaka, Bangladesh

*Correspondence: ullah1194@ gmail.com

This format hasn't been peer reviewed 


\begin{abstract}
This paper is purposed to delineate the current situation around Bangladesh as well as impacts of Coronavirus Disease-2019 (COVID-19) around the country and how the people over here are encountering this threatening pandemic. COVID-19 is an international epidemic that has got rapid wide-spread throughout different countries of the world to date. After its first outbreak in China different continents started to make sense and get aware against COVID-19 though, due to its special strategy of transmission several countries have been quite deteriorated preventing it. All the countries are moving at their best forward to find out any solution so that whole world could get rid of this horrifying situation as soon as possible. The authors here have reported an overview of how the outbreak of COVID-19 had put its commence in Bangladesh and to date how people over here have been tracing the way to tackle this havoc. Also, the changes that have brought around due to the crisis have offered us some fertile lessons that are enunciated here by the authors. To conclude, special considerations are anticipated to be highlighted pertaining COVID-19 outbreak in Bangladesh.
\end{abstract}

Keywords: COVID-19; Bangladesh; SARS-CoV-2; Outbreak; Pandemic

\title{
1. Introduction
}

With 5.17 million confirmed cases in 213 countries, the recent COVID-19 pandemic is intimidating the world population. Among the infected ones, 1.99 million people have recovered while 336 thousand infected individuals have already passed away. Hence, till date, the recovery and death rate are respectively reported $38.49 \%$ and $6.60 \%$.

This communicable disease is caused by Severe Acute Respiratory Syndrome Coronavirus-2 (SARS-CoV-2) strain of beta coronavirus (a subfamily of coronavirus). It is a newly emerged strain that binds to the ACE-2 receptor of ciliated bronchial epithelial cells as well as type-2 pneumocytes of human lung [1]. The origination of COVID-19 took place in China. More specifically, the initial outbreak of novel Corona virus was recorded in Hunan Seafood Market of Wuhan, Hubei Province, China. After the analysis of phylogenetic tree and multiple sequence alignment, it was estimated that, pangolin acted as an intermediate host in transmitting the novel coronavirus from bat to human.

The disease is transmitted to non-infected human from infected human's droplets which are generated during sneeze or cough. Also, direct respiratory tract contact or other respiratory secretions may cause this disease
[2]. The virus may stay for 2-3 hours in the air. In addition, if infected person touches any surface or object like phone, table, doorknob, laptop etc. it survives there for 8 hours and 2-3 hours in the air. The incubation period of this disease is 2-14 days. Novel coronavirus infects the upper and lower respiratory tract. Some mild symptoms of this disease are initially cold, cough, sore throat, mild muscle pain, appetite loss, fever and diarrhoea. The critical symptoms of this disease are: pneumonia, shortness of breathing and organ failure that may lead to death. People with comorbidity (having diabetes, blood pressure, heart disease and kidney disease) or acute respiratory disease like asthma, are more vulnerable to its infection $[3,4]$. In order to confirm whether a symptomatic or asymptomatic person is infected or not, diagnostic tests including RT-qPCR, serological test (Rapid diagnostic test or neutralization assay), CRISPR-CAS-12 are performed. Among them, RT-qPCR is the most frequently used test worldwide [5].

In the context of Bangladesh, the disease has already scattered to all 64 districts and the country is currently considered as the third highest in the number of people died among the South Asian countries till date [4]. With notable limitations, country's Institute of 
Epidemiology, Disease Control and Research (IEDCR) commenced the test for Covid-19 through the method RT qPCR and it became widespread across the country. The more the number of regular test increases, the more patients are found tested positive, in a proportional manner. However, mandatory lockdown was declared by Bangladesh government to prevent the severe community transmission in this densely-populated country but unfortunately, being a lower middle income country with people under poverty line, the lockdown is hardly maintained by day labourers, beggars, garment workers and so forth. Hence, social awareness about COVID-19 is found barely satisfactory in Bangladesh which should be brought immediately under sincere concernment by the government of Bangladesh.

\section{COVID-19 Outbreak in Bangladesh}

COVID-19 is an infectious disease that was identified for the first time in Wuhan, the capital of Hubei province, China in December 2019 and then it spread rapidly throughout the world [6,7]. After almost three and a half months of the first COVID-19 patient detected in China, three coronavirus cases (including two men and one women) have been tested positive for the first time on 8 March 2020 in Dhaka, Bangladesh [8] where two of them returned from Italy and the other is a relative of one of the returnees. Their ages were between 20 and 35 years, which was ensured by the Institute of Epidemiology, Disease Control and Research (IEDCR). They were hospitalized in Dhaka but the hospital name was kept secret. Three of the family members of them were being kept in quarantine after coming in contact with the COVID patients. 105586 total cases have been confirmed worldwide at that time [9]. Two of the COVID-19 patients had recovered after four days of first identified in Dhaka. On March 18, 2020 a total 14 cases (including 4 newly diagnosed) were confirmed and the first coronavirus patient died (Figure 1) in Bangladesh that was the 11th day of the country's first coronavirus case. The patient was a 70-year-old man who had several pre-existing complications like Chronic Obstructive Pulmonary Disease (COPD), hypertension, heart disease and diabetes. In the meantime, total confirmed cases were 191,127 along with 7807 death tolls [10]. To decrease the risk of acute respiratory infection transmission, WHO suggested some fundamental guidelines i.e. avoiding close contact with people who have acute respiratory infection symptoms, frequently washing hands (particularly if physical contact with patients or their environment), practicing etiquette rules like maintaining social distance, covering coughs and sneezes with disposable tissues etc., and enhancing standard infection prevention and control practices in emergency departments of the hospitals [11].

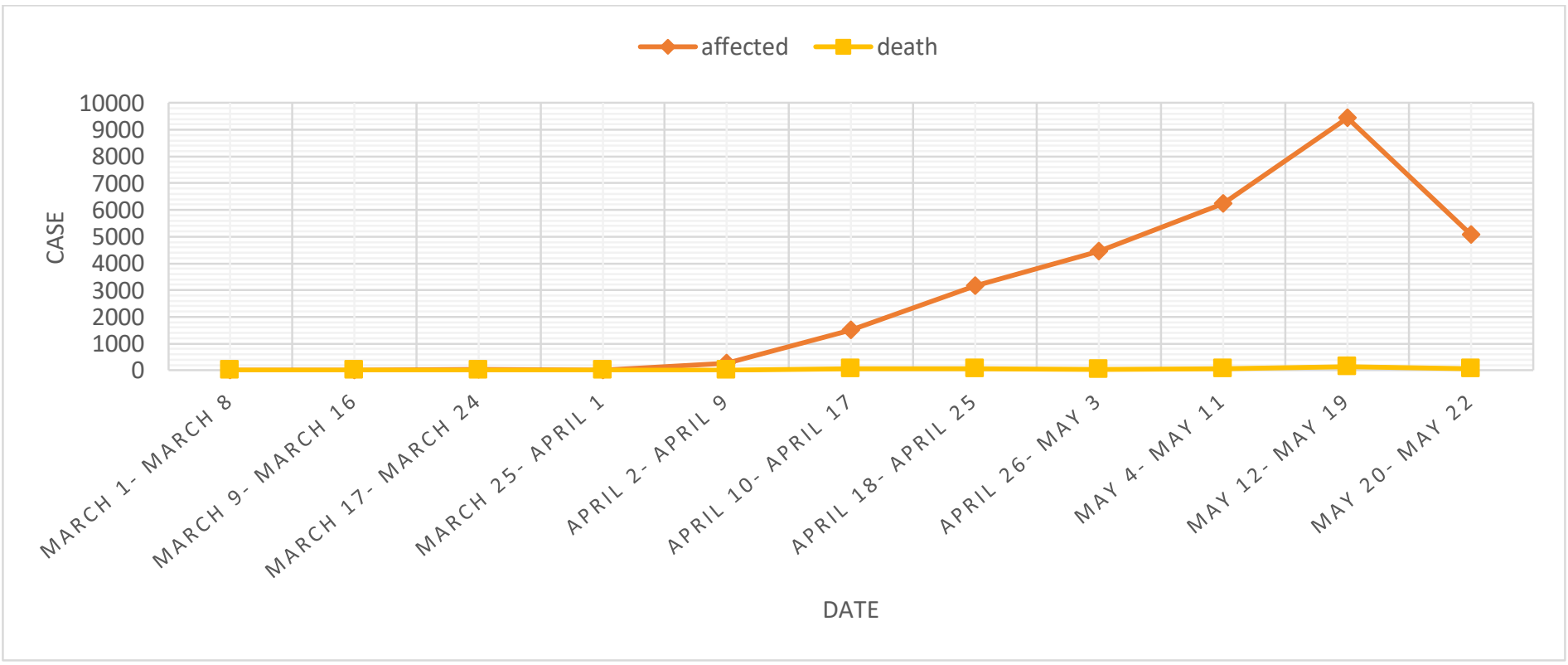

Figure 1: The graph depicts a comparison between total confirmed cases and total deaths due to COVID-19 infection from 8 March to 22 May, 2020, rolling an 8-day average in Bangladesh. (Directorate General of Health Service (DGHS)). 
The spread of coronavirus in Bangladesh commenced from Dhaka city to the rest of the country. Dhaka is the most densely populated city and capital of Bangladesh. Millions of people come and reside here from all over the country for their sustentation. However, the government declared a general holiday due to COVID19 infection from March 26 to April 4 to control the spread of the virus and ensure social distancing. But millions of people left Dhaka to enjoy the holidays with family and hardly maintained social distancing. Many people have been found gathering in Railway station, Bus-stand and launch terminal. That's how the virus has been spreading throughout the country due to community transmission. Right now, Dhaka division holds over 76 percent of the COVID-19 patients in the country, followed by Chattogram division holding 11.9 percent (Figure 2). In fact, the Dhaka district, belonged to Dhaka division, currently contains the highest amount of COVID-19 patients (79.03\%), followed by Narayanganj (Figure 3). Narayanganj, the neighbouring district of Dhaka city, has become the epicentre of coronavirus infection in Bangladesh since the majority portion of the patients started roaming around from here. Coronavirus patients have been detected in many districts who recently returned from Narayanganj.

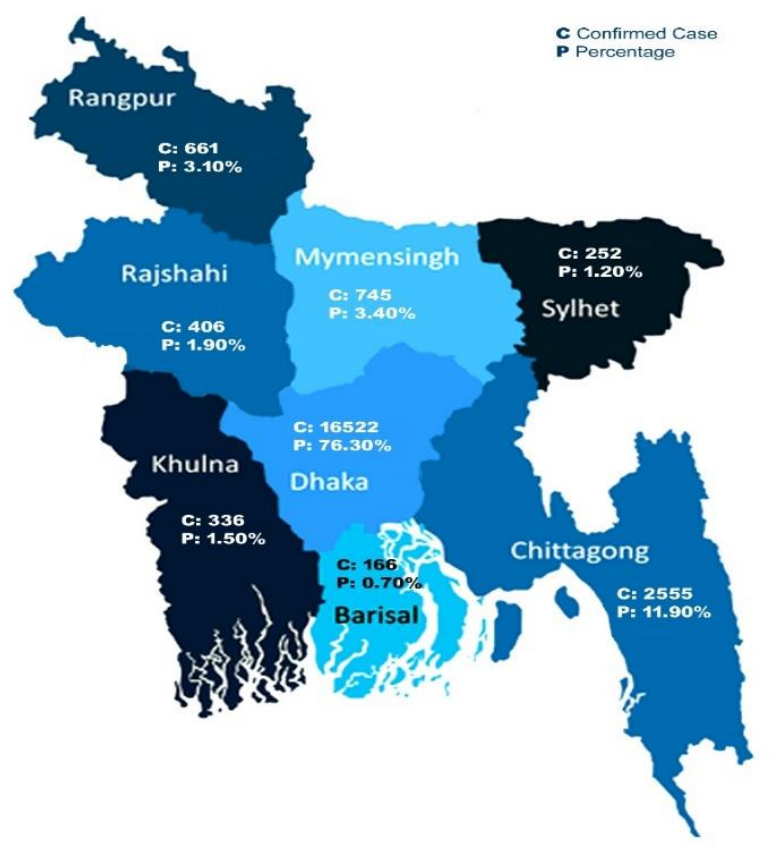

Figure 2: The map illustrates the geographical distribution of COVID-19 confirmed cases till 22 May (from 08 March) in Bangladesh along with percentage. (Source: Institute of Epidemiology, Disease Control and Research (IEDCR).

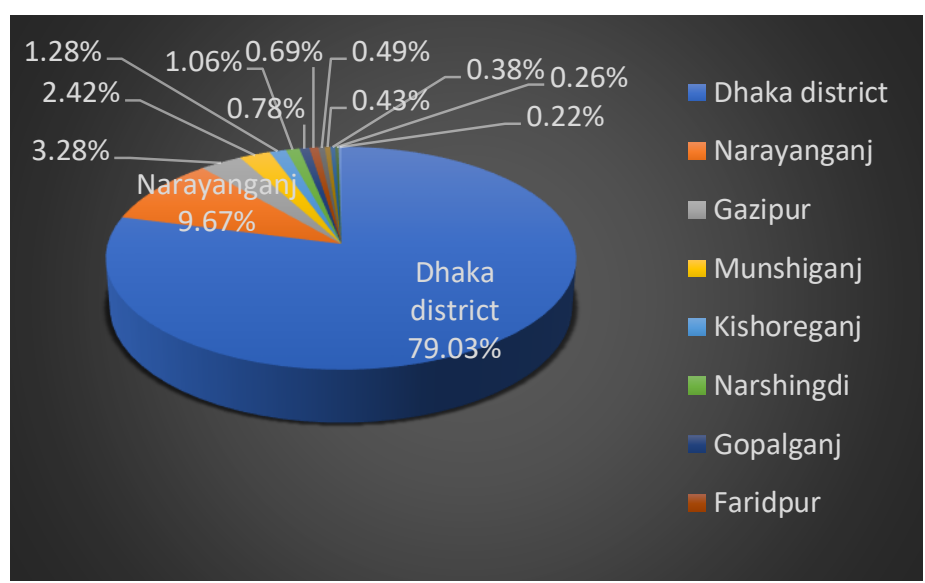

Figure 3: The total number of corona patients present in different districts of Dhaka division till 22 May, data compiled from

Directorate General of Health Service (DGHS).

The government has taken measures to prevent local transmission by locking down the transportation system (including Rail, Water, Air and Road transport). Bangladesh Police, Army, Navy, and Rapid Action Battalion (RAB) have been working on the frontline to ensure social distancing among the people and to keep an eye on the locked down houses around the country. All shops, super shops and kitchen markets throughout the country are declared by the government to be closed by $7 \mathrm{pm}$ and the grocery stores located in residential areas by 2 pm but drug stores and emergency services remained out of the purview of the orders.

However, at the end of April, a total of 7667 confirmed cases were found in Bangladesh with total of 168 deaths whereas total of 3,090,445 cases and 217,769 deaths found worldwide. From the beginning of May, a significant number of cases have been confirmed (on average 1000 per day) in Bangladesh. Even, the virus has recently been spread over the Rohingya refugees residing in Bangladesh right away. First COVID-19 case, as a result, was detected in the Kutupalong Rohingya refugee camp on May 14, 2020. However, currently, Bangladesh counts a total of 30205 confirmed cases till 22 May, 2020 (including 1200 health workers and above 2,000 police) and 432 deaths with 1.43 percent lethality rate. According to data compiled from the World Health Organization (WHO) and respective health ministries, Bangladesh is the 3rd highest country in death in South Asia after India and Pakistan (Figure 4). 


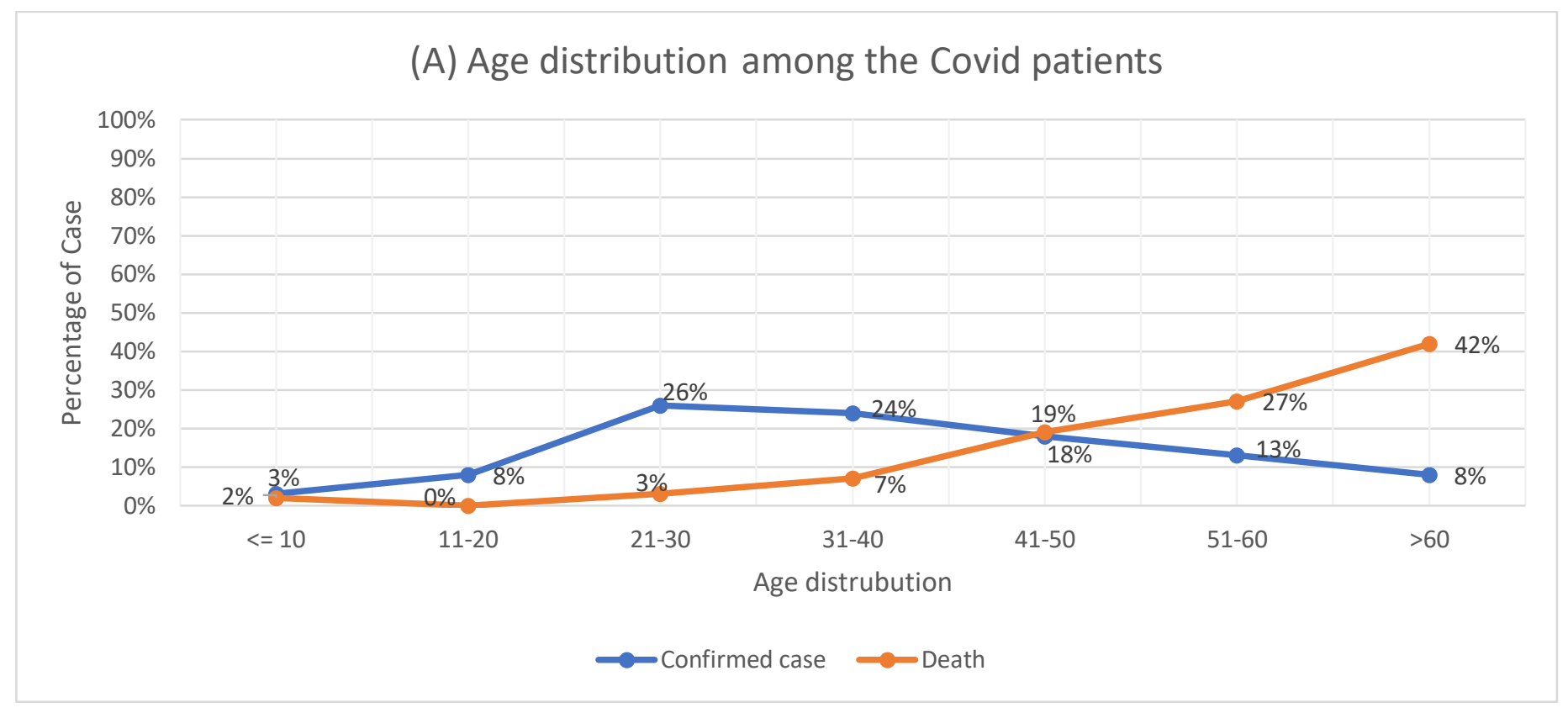

(B) Sex Distribution

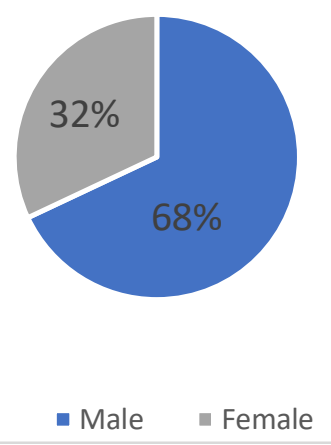

Figure 5: Age (A) and Sex (B) distribution among the COVID-19 patients in Bangladesh. Old people died mostly while young working-age people are more likely to get infected. Mortality rate and infection rate are higher in male than women. (Source:

Directorate General of Health Service (DGHS) and World Health Organization (WHO))

Evidence data suggests that people of all ages are infected with coronavirus in Bangladesh (Figure 5). Data compiled from the Institute of Epidemiology, Disease Control and Research (IEDCR) showed 50 percent of the COVID-19 confirmed cases found in Bangladesh are aged between 21 to 40 years. Surprisingly, young people within age 21-30 are found to be mostly affected with Covid-19 rather than the older and younger ones whereas Covid-19 kills mostly the older people throughout the world. According to the World Health Organization (WHO), older people and people with pre-existing complications such as chronic respiratory disease, diabetes, heart disease and cancer appear to be more vulnerable to becoming highly ill with the virus. The pattern, however, of COVID-19 death rates in Bangladesh appears to be discrete from that of the confirmed case rates. Death rate compared to age in Bangladesh is seen with a successive improve which depicts that, older people are more susceptible to the viral infection than the younger ones. Thus, when aged people remaining at high risk of dying, people of all ages, specially the younger ones are getting mostly affected due to their frequent outing or local transmission of the virus. However, when it comes to gender, male proportions have got infected and died mostly with coronavirus than the female proportions. 68 percent of total confirmed cases belonged to men and collaterally the death rate was 73 percent. Hence, 
the virus is killing more men than women worldwide [12]. The actual reason is not revealed yet by the scientists, but they suspect that, biological differences between men and women, unhealthy habits like smoking and underlying health issues among men could be influencing factors for this reason. To date 2,23,841 COVID-19 tests have been conducted till
May 22, 2020 in Bangladesh whereas the total number of confirmed cases were 30,205 so far (Figure 6).

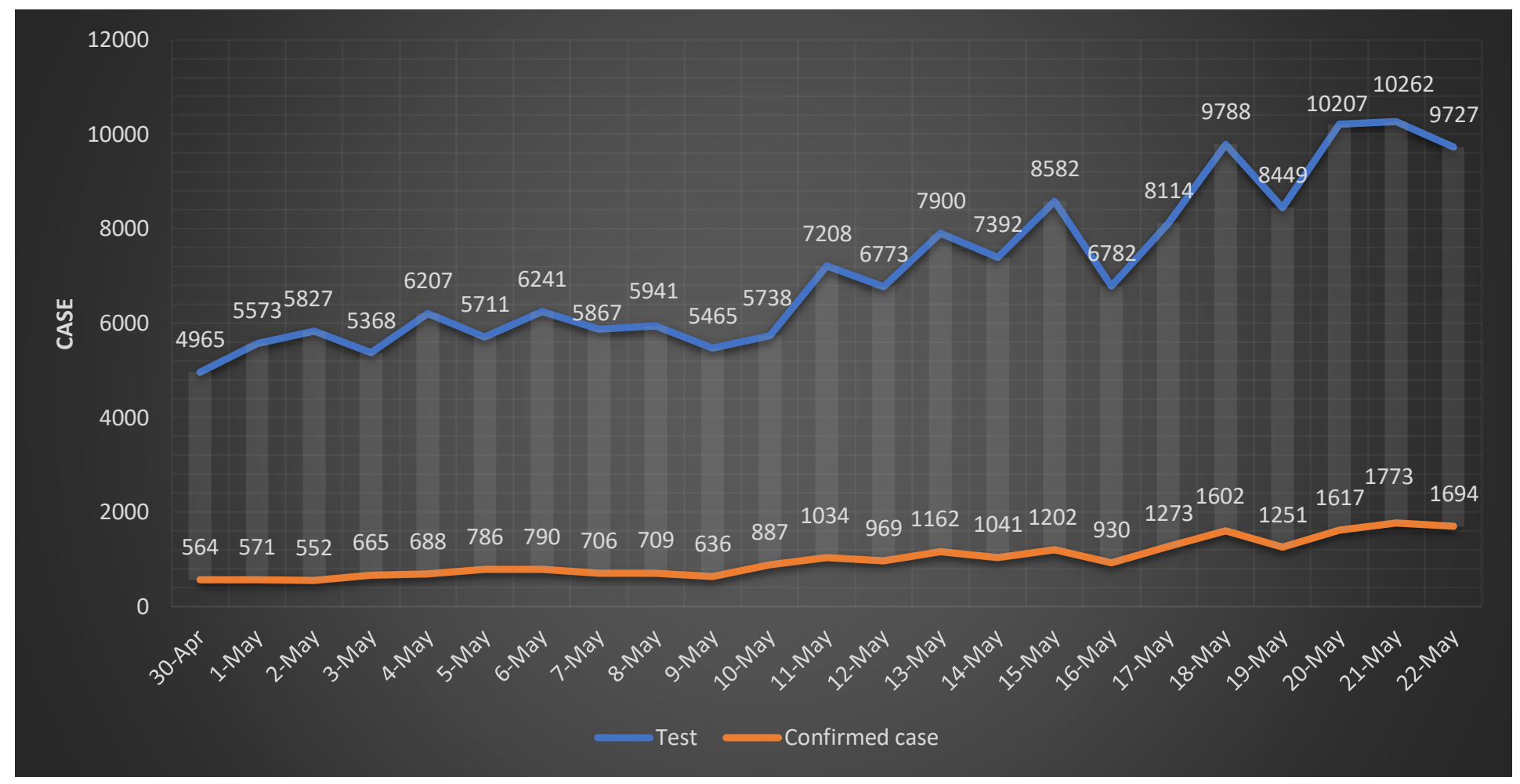

Figure 6: The bar graph shows a comparison between total COVID-19 tests and total confirmed cases from April 30 to May 22, 2020. The more tests conducted, the higher number of confirmed cases found.

At the beginning of the outbreak in Bangladesh, few tests were performed due to several limitations and so the positive cases were very low by then. But, since early of May, the amount of test as well as the laboratories and involved volunteers have been raised significantly and thus, the active cases have also been found massive. Till now, Bangladesh has got 42 COVID-19 laboratories across the country [13]. Unfortunately, Bangladesh has recorded the lowest recovery rate within the duration of first 53 days after Covid-19 infection, compared to other South Asian countries. But it started overtopping in a gradual manner since the beginning of May and the recovery rate proceeded at a considerably faster pace. However, a sharp and successive increase is shown in rate of confirmed case and death as well which is also a matter of concern as people aren't getting healed equally with the rate of active case. Currently, till May 22, the total amount recovery has reached around 6100 with 20 percent of recovery rate [14] (Figure 7).

Furthermore, the death toll has crossed the total of 400 on May 21 and thus, on an average, 11 patients have found dying per day in Bangladesh within the first 21 days of May which is quite breath-taking. Many people infected with novel coronavirus may not show symptoms and many of them died [15]. Interestingly, till May 22, 2020, around 550 people died in Bangladesh with showing COVID-19 symptoms including fever, cough or pneumonia whereas a good 
$\square$ Active case $\square$ Recovered case $\square$ Death

Case

$0 \quad 2000 \quad 4000 \quad 6000 \quad 8000 \quad 10000$

March 8- March 15

March 16- March 23

March 24- March 31

April 1-April 8

April 9-April 16

April 17-April 24

April 25- May 2

May 3- May10

May 11- May 18

May 19- May22

Figure 7: The graph shows a relationship between the days and the total number of active cases, recovered and death patients (source: The Institute of Epidemiology, Disease Control and Research (DGHS))

amount of people died with no COVID-19 positive test (Figure 08). However, through conducting a pilot survey via collecting news from national newspapers and electronic media, some cases have been found where patients tested negative before death but positive results have found revived after recollecting samples from dead patients. This may be the reason why many of the patients died with COVID-19 symptoms but with test negative. Henceforth, the fact could be further analysed and highlighted as well.

\section{Mystery of SARS-CoV-2 Genome isolated in Bangladesh}

The process of genome sequencing is simply the identification or determination of the whole DNA sequence of any organism which conveys the information about how genes are arranged within. It is quite important to understand the complete physiology of any organism i.e. novel corona virus and to track down the pathway of the virus by associating it with other metadata, thus to think about future prevention or treatment methodology against the virus.

80 countries have collected more than 24,000 genome sequence of SARS-CoV-2 so far, which include even countries like Nepal or Vietnam where the coronavirus problem is relatively less violent. In fact, in Bangladesh, the first incident was reported on March 7, 2020 by the country's Epidemiology Institute IEDCR. Nevertheless, due to a number of limitations, it took time to sequence the entire genome of the novel coronavirus from the sample from any Bangladeshi patient. However, for the first time in Bangladesh, from the Child Health Research Foundation (CHRF), Dr. Senjuti Saha, Dr. Samir Kumar Saha \& their team have broken the ground revealing the whole genome sequence of the coronavirus through using Illumina iSeq 100 NGS platform which has put a heavy influence on the research purview of the country. Accordingly, the news of the layout of genome sequence data became available on May 12. Hence, researchers started to explore it following the extraction of the sequence and information from the public repository GISAID and CNCB.

However, this virus has acquired nine mutations by now whereas seven mutations were very common among the sequenced viruses so far but surprisingly, this genome has got two new mutations which have not been seen among the viruses reported to date. This depicts that, the virus has already acquired these new changes after entering into Bangladesh which is quite horrifying.

\begin{tabular}{|c|c|c|c|c|c|}
\hline Position & $\begin{array}{l}\text { Reference } \\
\text { Base }\end{array}$ & $\begin{array}{c}\text { Mutated } \\
\text { Base }\end{array}$ & $\begin{array}{l}\text { Mutation } \\
\text { Type }\end{array}$ & $\begin{array}{c}\text { Protein: } \\
\text { Amino Acid } \\
\text { Change }\end{array}$ & $\begin{array}{c}\text { Mutation } \\
\text { Frequency } \\
(\mathbf{1 0 9 8 4 )}\end{array}$ \\
\hline 241 & $\mathrm{C}$ & $\mathrm{T}$ & $\begin{array}{c}\text { Upstream } \\
\text { Gene Variant }\end{array}$ & Non-coding & 7080 \\
\hline 1163 & A & $\mathrm{T}$ & Missense & $\begin{array}{l}\text { Orf1ab: } \\
\text { 300I>F }\end{array}$ & 1 \\
\hline 3037 & $\mathrm{C}$ & $\mathrm{T}$ & Synonymous & $\begin{array}{l}\text { Orf1ab: No } \\
\text { Change }\end{array}$ & 7104 \\
\hline 14408 & $\mathrm{C}$ & $\mathrm{T}$ & Missense & $\begin{array}{c}\text { Orf1ab: } \\
4715 \mathrm{P}>\mathrm{L}\end{array}$ & 7120 \\
\hline 17019 & G & $\mathrm{T}$ & Missense & $\begin{array}{c}\text { Orflab } \\
: 5585 \mathrm{E}>\mathrm{D}\end{array}$ & 1 \\
\hline 23403 & A & $\mathrm{G}$ & Missense & S: $614 \mathrm{D}>\mathrm{G}$ & 7145 \\
\hline 28881 & G & A & Missense & $N: 203 R>K$ & 1735 \\
\hline 28882 & G & A & Synonymous & $\begin{array}{l}\text { N: No } \\
\text { Change }\end{array}$ & 1731 \\
\hline 28883 & $\mathrm{G}$ & $\mathrm{C}$ & Missense & $\mathrm{N}: 204 \mathrm{G}>\mathrm{R}$ & 1730 \\
\hline
\end{tabular}

Table 1: Genotypic differences among different SARS-CoV-2 isolates found in Bangladesh.

Again when observed closely, among those nine mutations within the viral genome, one was found which results in a non-silent mutation in its Spike protein. The mutation utterly leads to an amino acid change i.e. Aspartate to Glycine at the 614th position of the Spike protein (D614G). It is predicted that this mutation of the virus has the cause for spread out quickly among the European and American populations. This creates an extra serine protease or 
elastase cleavage site close to the Open Reading Frame (ORF) S1 and S2 junction of the Spike protein (Table 1). Furthermore, phylogenetic tree (UPGMA and Neighbour-Joining) has been constructed with 350 sequences from different countries and reference sequence to understand the origin of the virus. The tree utterly delineated that, Bangladeshi SARS-CoV-2 genome isolate is familiar to the European cluster which means that, perhaps the person got infected by someone who returned from Europe.

However, afterwards researchers across the country started retrieving more sequences incessantly e.g. on May 20,2020 Bangladesh has got another sequence from National Institution of Biotechnology (NIB) under the lead of Dr. Md Salimullah. Interestingly, their sequence has showed to be compatible with that from United States, Spain and Italy. Successively, Bangladesh Jute Research Institute \& Chittagong Veterinary \& Animal Sciences University (CVASU) has deposited another sequence by May 21, 2020 under the lead of Dr. Abdul Razzak which showed its uniformity with the sequence of Saudi, Arabia, Russia, Australia and United states. Again, on the next day, Dhaka University has further added another one under the instruction of Sharif Akhtaruzzaman.

Hence, researches are concertedly going on across the country to explore the genome and thus trying to come to an end. So, this issue should immediately bring under sincere concern by the government as soon as possible.

\section{Impacts of COVID-19 throughout Bangladesh}

\subsection{Impact on the Overall Economy}

Economy of Bangladesh has a high dependency on garments and agricultural sector. Being a low medium income country, it may face economic crisis due to COVID-19 pandemic. Last year, garments industry contributed to $84 \%$ of the country's exports that worth $\$ 40$ billion. But this year due to lockdown situation, this industry has to cancel numerous orders and hold off orders worth nearly $\$ 3$ billion. At present, 450 spinning mills, 850 weaving mills and 250 dyeing factories which are directly linked to the Garment industry are at risk of loss. Around 10 lack people are employed in these mills. Garment sector is also related to packaging industry which is also affected by COVID-19 situation.

Moreover, 59 banks and 46 general insurance companies count on the garment sector for running their business. As a poverty alleviation scheme, government has declared over 1.0 trillion BDT (over 11 billion USD) which is nearly 3.6 percent of Bangladesh's gross domestic product (GDP) for various sectors including the agriculture and garments. This will provide soft bank loans and aid people that are victim of COVID-19 situation.

Transport sector is having difficult times in this pandemic. The number of trucks and lorries had surged remarkably with the pace of the country's nearly $\$ 100$ billion exports and imports. But the to this sector may become jobless in this hard situation.

According to the estimation of Dhaka University Health and Economy Institute, from 26 March to 26 April, the total loss in economy was around 100,000 crores. There is a loss of about 3300 crores in agricultural (200 crore), industrial (1131 crore) and service (2000 crore) sector and the loss will increase with the extension of lockdown.

The experts found out that export and import economy has come to a standstill. Bangladesh will get poorer if the lockdown continues for a long time. In town hawker, rickshaw puller, auto rickshaw driver, bus driver, waiter, day labourer and in the village, farmer, fisherman, trucks and lorries are static due to lockdown situation. There is a chance that 10 lakh people related, shopkeeper, emigrants will face hardship in their daily lives. $40 \%$ poultry industry is driven by woman and it may face loss of 3350 crore taka according to the Bangladesh Poultry Industries Central Council.

During COVID-19 epidemic, unemployment of Bangladeshi emigrants is reflecting a negative impact on remittance. The remittance is reduced by 36 crore dollars within the last 2 months which is also hampering the overall economy of Bangladesh. World Bank (WB) has recently reported that, due to COVID- 
19epidemic and shutdown, remittance may decline by almost 22 percent in this financial year of 2019-2020 in Bangladesh and thus, it could come down to $\$ 1,400$ crore in 2020, which was $\$ 1,830$ crore in 2019.

Besides all these, price hike of daily commodities has also been added to the economy. Daily essentials are subjected to price hike amid COVID-19. Due to supply disruption and scarcity of kitchen market, the prices of oil, rice, flour are surging. The price of edible oil has witnessed 8-10\% rise. Moreover, 38-70 BDT per kg rice is being sold in markets. However, the Government will launch a special open market sale of coarse rice at 10 BDT per kg across city corporation for the poor people.

\subsection{Impact on Agricultural Sector}

Agriculture is the backbone of economy of Bangladesh. According to World Bank, it is the income source of $87 \%$ rural people. In fact, $11 \%$ city dwellers are also directly related to agricultural sector. Around $45.7 \%$ labour power are recruited in farming. Not only that, the contribution of agriculture on GDP of Bangladesh is $16.6 \%$. This information indicates the importance of agriculture for Bangladesh. The national lockdown strategy is imposing a bad impact on overall economy. Many farmers are unable to work on their lands, also, are not accessible to some markets for selling their agro products. Moreover, severely hampered transportation, inadequacy of labour and price hike can act as impediments in the fresh food supply chain.

In poultry industry, 83000 poulterers with investment of 42000 crores are facing heavy loss due to ongoing country-wide lockdown for COVID-19 pandemic. Their daily egg production is 4.25 crore and because of fall of demand, they have to sell $1 / 3$ of total eggs at $45 \%$ lower price. In overall poultry farms, 3500 tons of broiler chicken production/day takes place. According to the Bangladesh Poultry Industries Central Council, the price of broiler chicken has fallen to 55 BDT $(0.65$ USD) per kilogram. Demand of broiler chickens dramatically dipped in lockdown situation and 1.65 crore 1 day old chicks are discarded every week to mitigate loss. More importantly, jobs of 47 lakh workers in poultry industry is endangered right now.
The country's dairy and fish producers are facing huge number of economic loss. Total number of dairy farms country-wide is about 2.50 lac. Per day milk produced and supplied for selling is 1.5 crore litres. But due to lockdown strategy, the transportation has become limited and also customer demand plummeted. Milk price has dropped by around 35 percent and 25 lakh litres are remaining unsold. The employment of 1.2 crore people is at risk in dairy sector.

The demand for fish substantially plunged. Consequently, many hatcheries are closed down. Also, crab, shrimp, and fish producers are facing frequent trade embargo that is resulting in economic loss. For example: Bangladesh exports $70 \%$ of the crabs in the Chinese market. Lockdown has stopped the exportation. Hence crab industry of Bangladesh is going to face significant loss. Production of dry fish are also reduced by 40 percent due to the corona epidemic.

In order to sustain food security and socio-economic development, the vulnerability of farming communities should be lessened by the Government and nongovernment organisations.

\subsection{Impact of COVID-19 on Mental Health of the Patients}

Mental health of a person includes emotional, psychological and social well-being. For a COVID-19 patient, the negligence of surrounding people and social discrimination is worse than COVID-19 disease itself. In our country, in several cases, if a person is confirmed as COVID-19 positive, he including his family members are subjected to harassment of neighbour and society and sometimes they are ostracized or forced to leave the society.

Besides all these, a COVID-19 patient remains over stressed and nervous conditions. After getting admitted into hospital, the patient may witness deaths every day in his ward which may affect his mental strength badly. To encourage patients of COVID-19, the doctor, nurses should be compassionate to them. Sometimes courage can help the patient in early recovery. 


\subsection{Influence of COVID-19 on Education System}

The total number of students in Bangladesh is approximately 23907151. Among them, primary, secondary and post-secondary level students are consecutively 16230000,7400000 and 277151.To tackle the breakout of COVID-19, the government declared closing down of all educational institutions on 18 March, 2020. Not only that, Higher Secondary School Certificate examination was postponed by Ministry of Education.

Prime minister Sheikh Hasina also declared that if COVID-19 situations don't get better, all institutions will remain close until September. This closure for a long period can cause some problems:

The public and private universities may face session jam if the classes and exams are not taken on time. Some universities have semester system, which means six months per session. So, there is an immense possibility of session jam in almost all universities.

Many schools, private universities and a few public universities are taking online classes in order to prevent the session jam. But, this is not actually a fair way for taking classes according to many students and teachers. Bangladesh do not have a strong platform for taking online classes. Teachers are using meeting applications such as ZOOM for taking classes. Moreover, access of internet requires data purchase or $\mathrm{WiFi}$ connection. Students who live in remote areas do not have stable network. Also, data purchase is not possible for students who are under financial crisis due to COVID19 pandemic. As a result, some students of a specific class are deprived of online classes. Also some students are indifferent to joining online classes due to lack of social interaction between students and teachers. HSC examination has been postponed which may delay the admission of college students in universities and other institutions.

Bangladesh Government has taken some steps such as: keeping the universities, schools and colleges open on holidays that means taking classes for all 7 days of week after the lockdown strategy cancellation. Also, UNICEF is working along with Bangladesh government to offer fruitful remote learning programmes through $\mathrm{TV}$, mobile phone and Internet platforms for 42 million school students. UNICEF has also aided in producing guides to help teachers performing online classes. Notwithstanding, Bangladesh government and educational institutions should come forward to provide with proper facilities for online classes, i.e., ensuring financial support for students.

\subsection{Impact of COVID-19 on Culture and Religious Beliefs}

The lockdown strategy taken by government due to COVID-19 outbreak has been extended several times. Religious gatherings have been proved to be a medium for spreading the COVID-19.

Performing janazah salah at a large scale gathering is prohibited by government. But violating it, around 100000 people gathered in the janazah of Maulana Jubayer Ahmed Ansari, a popular Islamic teacher of Rahmania madrassa. In addition, Millions of people had expectations to congregate in mosques for performing tarabi prayer during Ramadan. Similar to the order of Saudi government, Bangladesh government allowed only 12 people in a mosque including mosque officials and advised majority of people to perform prayer at home.

Moreover, many people go for shopping during Eid season. In order to prevent community transmission, most of the markets and supershops such as Bashundhara, Jamuna Future Park, Newmarket and shops all over the country decided together to keep shops closed during Ramadan. Inspite of all these, small group of people are still going for shopping by neglecting COVID-19 situation. Furthermore, any kind of arrangement of iftar (evening meals that mark the breaking of the fasting) party or any gathering on Eid has been banned by the government. Not only that, some people are still returning their village home from the town and thus getting crowded at the docks which has recently brought under concern by the government. Hence, docks have been closed and transport availability has been lessened in greater amount by the law enforcement forces. 


\subsection{Impact of COVID-19 on Lifestyle}

According to recreational point of view, various concerts, shooting for movie, telefilms and drama on the occasion of Eid has been cancelled for reducing public gatherings. People are spending time on social networking sites and interacting with dear and near ones. The lifestyle of people has literally changed because of long time lockdown. Some people are working online and those who are on leave or students, are spending time on television and online applications like YouTube, Facebook etc. Besides all these, family members are spending time with each other previously which was difficult for their tight work schedule. Thus, their relationships are getting stronger. Most people are shopping from online whether it's household commodities, food items or clothing for Eid. Right now, some online streaming services like Netflix, Amazon Prime Video etc. has become very popular among people worldwide.

In short, pandemic has brought about changes at every phase of regular life.

\section{How Bangladesh is Encountering COVID-19}

"30,205 confirmed cases and 432 deaths"- this is the report of IEDCR till 22 May, 2020. At the beginning of diagnosis, that means in the second week of March, Government declared shutdown of all educational institutions. Observing the deterioration of condition day by day, Bangladesh government later announced lockdown except for pharmacy, banks, food markets and hospitals. However, 20.5\% people of Bangladesh live under poverty line. Hence, most of them can hardly maintain the lockdown orders throughout the country. Moreover, some people are socially unaware of the gruesomeness of this disease worldwide. By not taking the COVID-19 situation seriously, they are unnecessarily violating the lockdown rules. Again, due to inadequacy of COVID-19 diagnosis per day, suspected COVID-19 patients (according to symptoms) are dying without treatment also, risking the life of their family members and relatives. Many non-infected patients are also deprived of treatments. If they have COVID-19 symptoms, no hospital is getting them admitted without diagnosis report, consequently they are dying untreated.

\subsection{Diagnosis Status of Bangladesh}

\subsubsection{Inadequacy of Test}

To date, no specific medicine or vaccine is discovered to treat the unstoppable virus, only symptomatic treatment is available. Hence, COVID-19diagnostic testing has become indispensable. Diagnosis of suspected COVID-19 patients, contact tracing, ensuring quarantine (if necessary, aided by police) for people who came in contact with confirmed patients and isolation of patient-these are the remedy for preventing community transmission of covid-19 right now. But, the number of tests conducted by IEDCR and other 42 institutions or labs of Bangladesh are not sufficient. To be more clarified, the population of Bangladesh is 170 million and 1313 per million people are being tested (until 22 may,2020). On the other hand, India is populated with around 138 crore people and total conducted test per million is 1,540. Total test conducted by India is more than 2 million whereas it's 223,841 for Bangladesh until 22 May, 2020. Both the Asian countries are lower income countries, yet India is far much ahead in case of testing capability of COVID-19 than Bangladesh. It is a matter of concern that a huge number of patients are remaining undetected everyday which may worsen the situation day by day. However, the number of detection is increasing every day and synchronously positive cases are also rising. Unfortunately, the test of all the suspected cases per day cannot be performed and they need to wait for call helplessly for days or weeks. Meanwhile, some undetected people die with COVID19 symptoms and later their samples are tested to ensure the cause of death. However, the suspected and asymptomatic as well as those who came in contact with patient should be tested without any delay by increasing the number of tests. This insufficiency of test is due to lack of experienced individuals for detecting COVID-19. Also, different universities and research organisations holding PCR machines are involved in COVID-19 detection that are not adequate enough to run the test of all the patients altogether. Some machines are also previously damaged, which 
may not show result with accuracy However, the collaboration of more institutions (research and educational) and laboratories (public and private) should be ensured by the government for rapid test of COVID-19 as early as possible.

\subsubsection{Paucity of Protective Equipment}

In order to prevent infection caused by COVID-19, specialized garments are required which are collectively called Personal Protective Equipment (PPE). It includes face shield, glove, gown, goggle. According to WHO (until 18 May,2020), the stocks of PPE is 1,375,232 and amount of masks and gloves are sequentially 2,515,110 and 691,386. The number of PPE is inadequate for doctors, nurses, COVID-19 diagnosis volunteers and other health service providers. Again, police and army are also in need of PPE who are controlling the lockdown situation. Reusing these PPE is also a matter of great risk and requires caution during cleaning. Already many of the health workers including doctors and nurses are infected with COVID-19. Insufficiency of safety equipment are somehow affecting the treatment facilities of Bangladesh. These health workers are the frontline fighters who are in need of PPE for treatment of COVID-19 patients and general patients as well. So, Government should take immediate steps for increasing the production of PPE garments nationally for ensuring the health of health workers that are working relentlessly.

\subsubsection{Lack of Skilled Manpower}

From collecting sample to testing, the laboratories of institutions and hospitals that are involved in COVID19 detection, are facing difficulties at each step. The reason behind it is deficiency in skilled manpower and relevant logistics. According to a virologist of Dhaka Medical College, One RT-PCR thermal cycler that is placed at DMC virology lab has the capacity to conduct 188 tests per day, which is the maximum amongst other RT-PCR cyclers in Bangladesh. Notwithstanding, virologists need to collect about more than 300 samples each day in order to handle the pressure of patients. Properly collected samples are mandatory for accuracy of result. But there is scarcity of human resources for collecting sample from nose and mouth. Also, if the samples are not collected and preserved in a proper way, report may show false positive or false negative result.

According to health experts, some semiskilled technologists are working at different labs set up outside Dhaka since there has been no recruitment of technologists for a long period. Example of a negligent: The result of 30 samples turn out to be positive in tests conducted in Jesshore and Kushtia. But their further test that was carried out in Dhaka demonstrated negative result. So, this incidence raises a question over the capability of lab set up and their semi-skilled technologists at some districts. Only a few skilled workers have been recruited with a short-term contract.

Sample preservation is hindered due to lack of sophisticated refrigeration $\left(-80^{\circ} \mathrm{C}\right.$ required). If preservation is improper, it can degrade the sample quality and affect test result.

Skilled biotechnologists and students of life science background came forward as volunteers for detecting COVID-19 by RT PCR assay. They should be provided with proper PPE for ensuring their protection as they are fighting from frontline in this pandemic. Again, more biotechnologists, biochemist, microbiologist and virologists should be trained properly so that they can contribute in the critical moment of nation by detecting COVID-19 patients. Biosafety levels of lab, contamination etc. should be taken under deep observation.

\subsubsection{Treatment Facilities All Over the Country}

Bangladesh is an overpopulated country compared to the number of its health care providers. Modern treatments are also not available in each corner as Bangladesh is not much developed. There exists the lack of availability of necessary equipment and machines required to deal with COVID-19 pandemic. As a result, there is a possibility that many COVID19 patients may die without treatment.

\section{Death of Health Service Providers}

Currently, doctor and patient ratio in Bangladesh is 1: 2500 , that is the 2nd lowest among South Asian 
countries according to the WHO. Around 2,000 doctors and 6,000 nurses are appointed for treatment of COVID-19 by health ministry. However, some doctors and nurses in different hospitals are not feeling secure as PPE don't have much availability, hence showing less willingness to work. In addition, many patients hide their location and symptoms from doctors for ease of hospitalization which becomes a matter of risk for doctors and nurses. Most horrifying news is, over 1200 health workers are found positive in COVID-19 test until 22 May, 2020.Till date, 3 doctors died due to COVID-19 infection. First of all, there is scarcity of doctors and nurses. Secondly many of them are being infected daily due to exposure to confirmed or suspected COVID-19 patients. In fact, due to all these incidents, non-infected patients are also dying without treatment.

However, incentives are declared by government for doctors and nurses who will treat the COVID-19 patients. Not only that, training programmes are arranged for health workers for aiding and treated COVID-19 patients of distant areas.

\section{Availability of Hospitals and Equipment}

Some public and private hospitals are approved by government for the treatment of COVID-19.

The following hospitals are providing services for COVID-19 patients:

1. Kuwait Bangladesh Friendship Government Hospital

2. Kurmitola General Hospital

3. National Chest Infectious Diseases Hospital

4. Dhaka Medical College Hospital

5. Bangladesh Railway Hospital

6. Mohanagar General Hospital

7. Sheikh Russel Gastro Liver Institute \& Hospital

8. Sajida Foundation Hospital

9. Mirpur Maternity Hospital

10. Jinjira Specialized Hospital

11. Amin Bazar Hospital

12. Kamrangirchar Hospital

13. Chittagong Medical College Hospital
14. Bangladesh Institute of Tropical and Infectious Diseases

15. Bashundhara COVID-19 Isolation Hospital (second largest COVID-19 hospital in the world)

16. Government Mugda Hospital

17. Nitor Hospital

Apart from above hospitals, some other hospitals are also involved in the treatment but at a small scale.

In Bangladesh, COVID-19 infection rate is 177 per million people. Unfortunately, Bangladesh doesn't possess adequate number of ICU, Isolation beds, ventilators, dialysis unit for treating the increasing number of patients. Bangladesh has only 1,240 ICU beds (432 in govt. Hospitals and 808 in private hospitals). On calculation, only 0.73 beds are available for 100000 people. In total 9134 isolation beds and 102 dialysis units are available. Besides all these, insufficient number of ventilators are present for respiratory support of critical patients. Only 1,840 ventilators are present in Bangladesh which indicates that 1 ventilator is available for 92,391 people. Most of the hospitals that have ICU and ventilators are situated in Dhaka. So, in case any patient becomes critical in remote area, his/her chance of survival may reduce.

However, the government and nongovernment organisations should come forward to ensure importation of more ventilators and instalment of ICU in order to increase survival rate of critical COVID-19 patients.

\subsubsection{Newly Emerged Treatments}

\section{Plasma Therapy}

Plasma therapy is providing a light of hope for COVID19 patients. This procedure involves collecting blood sample from a fully recovered COVID-19 patient and transfusing plasma to a critically ill patient. Blood cells are absent in plasma and it contains only antibodies and other proteins. The immune system of an infected person produces natural antibodies in order to fight the virus(antigen). The antibodies increase in number over time in the plasma of an infected person and he gets cured. In plasma therapy, the antibodies are used to treat other infected patients. Currently, Dhaka Medical College Hospital (DMCH) has started collecting 
plasma from COVID-19 recovered patients for clinical trials of Convalescent Plasma Therapy (CPT). Dr Md Dildar Hossain, a medical officer at the Shaheed Suhrawardy Medical College and Hospital's kidney diseases department was the first donor of plasma. He was diagnosed with COVID-19 on April 25 and later fully recovered on May 9. Finally, he voluntarily donated his plasma. Another physician was also reported to donate plasma at $\mathrm{DMCH}$ for saving lives of COVID-19 infected patients.

\section{Breakthrough of Possible Discovery of Treatment}

The World Health Organisation has chosen an antiviral drug called Remdisivir after couple of experiments which is an antiviral drug that was used for the effective treatment of Ebola. This drug showed positive result against SARS-Cov-2 in an experiment conducted on model animal [16]. However, in Bangladesh, hospitals are using some controversial medicines such as hydroxychloroquine, chloroquine, Azithromycine for the treatment protocol of COVID-19. But Beximco Pharmaceuticals has launched the first generic version of antiviral drug Remdesivir, named Bemsivir for the first time in the world on 21 May, 2020. Remdesivir is a drug that inhibits viral RNA synthesis and thus it stops replication of SARS-CoV-2 [17]. U.S. FDA has allowed it as "Emergency Use Authorisation" for the treatment of COVID-19 patients.

Another approach was from Professor Dr Tarek Alam, head of medicine of Bangladesh Medical College and Hospital, who along with his team frequently used antiprotozoal medicine named Ivermectin in a single dose with an antibiotic called Doxycycline that demonstrated an astounding result in curing some COVID-19 patients. Around 60 COVID-19 positive patients with respiratory issues were prescribed the drug by Dr. Tarek and his medical team. After second test of those patients in IEDCR, it was confirmed that the patients who were under the research turned out to be COVID-19 negative. According to Dr. Tarek and his medical team, they were recovered within 4 days after applying the combination of medicine. These drug combinations will not cause any side effect. According to them, the overall cost for medicine is approximately
30 BDT. For the approval of their medicine, they have contacted DGHS (Directorate General of Health Services) and other government organizations. Also, the trials and study for success rate and side effects have already been commenced by DGHS. If it turns out to be successful, it will be a global breakthrough discovery by Bangladeshi doctors in the history of corona treatment.

\subsubsection{Social Awareness Status in Bangladesh}

\section{Community Transmission Can't Be Prevented}

Till date, there are 30,205 confirmed cases of COVID19 according to IEDCR. All 65 districts of Bangladesh had COVID-19 patients as of 22 May, 2020. According to many positive cases, none of them were immigrant nor any of their family members or relatives returned from abroad. Hence, it is a vivid indication that community transmission has begun. Many people are not concerned about dreadfulness of this disease. They are unnecessarily going out of house to the markets for shopping and are not abiding by the WHO protocols properly. The community transmission exceeded in Dhaka, Narayanganj and Chittagong because people of these districts however violate the lockdown and many emigrants did not maintain quarantine. Also, social distancing is a very difficult task in a densely populated country like Bangladesh. As a result, the number is increasing exponentially day by day. Again, some people died who were suspected to be infected with COVID-19. Later, many of their result turn out to be positive for COVID-19. Some deaths were recorded in the district isolation centres. At the beginning, tests of suspected ones were only conducted in IEDCR. Later, government provided with testing facilities in other divisions. In order to decrease the community transmission, there is no alternative to increasing test for COVID-19. So, the test facility should be ensured for people all over the country for prohibiting the community transmission as soon as possible.

\section{Reasons behind the Vulnerability of Bangladeshi People throughout the Country}

According to Bangladesh Bureau of Statistics, 3 crore and 40 lack people are poor in Bangladesh and 1.75 
crore people among them live below poverty line. Poverty is a root cause indicating why people are violating lockdown. People who are at high risk of COVID-19 infection are: elder people(age group more than 50), day labourers and people with comorbidities. Susceptibility to this disease is much higher for elder people as their immune system is weak for producing antibody against corona virus. Therefore, they require intensive based treatment and ventilator. Some Day labourers, rickshaw pullers, hawkers, garment workers are more exposed for this infection because they need to go outside for daily earning unless they have to starve. They live in slums which is not a clean place and might increase the possibility of infection. Besides, beggars do not have houses to live in which makes them vulnerable to infection. In addition, aged people should not go outside for working in office, factories, shops etc places because every day they might come in contact of their colleagues and others. Imperative support such as fundamental daily needs such as food, relief, rehabilitation for deprived people may abate their hardship and decrease the possibility of getting infected or infecting others. For example, the government has announced over $\$ 11$ billion stimulus package for various sectors including the agriculture and garments to provide soft bank loans and to aid people that are victim to COVID-19 situation.

\section{Bangladesh Has Got Rohingya Refugee}

More than 1.1 million rohingya refugees are present in Cox bazar.They are living in camp which is constrained and there is a risk that if a few refugees are infected,it will be devastating for the whole camp.Again,3.3 million local people abide in Cox bazar.A news that is horrifying the people is one confirmed case of COVID19 till 14 May, 2020. If somehow community transmission takes place, the number of patients will exceed and many people will be succumbed to death.Also,there is lack of ventilators in Cox bazar. Only 10 Intensive Care Unit (ICU) beds are available for 1.1 million people in one local hospital. However,social awareness should be raised properly in Rohingya camps and number of ventilators and ICU should be increased in nearby hospitals to tackle upcoming crisis.

\section{Special measures from the Government of Bangladesh}

Due to this epidemic, not only the governmental organizations but also the non-governmental or private organizations are trying altogether to fight against this novel pandemic concertedly. Different social organizations were always aware with any kind of immediate steps and still proceeding with serving the defected and deprived people in various ways. However, our government was concerned since the outbreak was commenced in Bangladesh and still trying to fight with this pandemic in different probable ways. The momentous measures taken by the government are depicted below in brief.

Government, on January 22, 2020, initiated screening of all the travellers from China at Hazrat Shahjalal International Airport in Dhaka, Bangladesh by the thermal scanners immediately after the news of the pandemic had just spread out. Following that, onarrival visas for all the Chinese visitors were revoked and precautionary measures were taken in Chattogram port as well on February 2,2020. On March 8,2020, due to abrupt spread of the pandemic, our government cancelled the grand inauguration ceremony of father of the nation of Bangladesh Bangabandhu Sheikh Mujibur Rahman's birth centenary celebration program to avoid public gathering and it was preplanned to be held on March 17. Educational institutions were annunciated, on March 16,2020, to remain closed until March 31, 2020, which is still continuing. On March 18, 2020, the National Preparedness and Response Plan (NPRP) for COVID-19 was declared by the government. Accordingly, the first lockdown was declared at Shibchar of Madaripur district on March 19, 2020 which is still remaining. Consequently, all the state public programs including the celebration of 50th Independence Day and Bangla New Year were announced to be closed this year. On March 22, 2020, the Prime Minister of Bangladesh determined to generate a 'SAARC COVID-19 emergency fund' and also committed to contribute USD 1.5 million to fight 
against novel pandemic COVID-19 among SAARC regional countries. After that, all the public examinations were cancelled. Government and private offices except the emergency services were strictly ordered, on March 23, 2020, to be closed immediately from March 26 until April 4, 2020. As the situation remained unchanged, on March 24, 2020, the government announced a 10-day initial ban on all the public transports from March 26,2020 till April 4, 2020 which was further extended and still continuing. Accordingly, on March 27,2020 Civil Aviation authority of Bangladesh suspended all their domestic and international flights with 15 countries including India, Malaysia, Kuwait, Oman, Singapore, Qatar, Saudi Arabia, Turkey, United Arab Emirates, Bahrain, Sri Lanka, United Kingdom, Honk Kong, Bhutan, and Thailand till 30 May, 2020. Government also announced several stimulus packages to different sectors that are jeopardized due to the pandemic.

\subsection{Economic Stimulus Measures}

Especial economic measures taken by Bangladesh Bank is given below.

- Bangladesh Bank (BB) reduced required Cash Reserve Requirement (CRR) of other banks from $5.5 \%$ to $4 \%$ on bi-weekly average basis and $5 \%$ to $3.5 \%$ on daily basis feasible from 15 April. Repo interest rate also reduced from $6 \%$ to $5.25 \%$ that was effective from 12 April.

- The banks were instructed not to deduct any charges against late payment of credit card bill during the pandemic.

- Bangladesh Bank postponed charging interest on loans from customers.

- BB permitted foreign owned companies to take short-term loans from their parent companies.

\subsection{The Financial Packages Annunciated by the Government}

\section{Package-1}

A loan facility of approximately USD 3,529 million, with the interest rate of $9 \%$, generated to provide working capital facilities to the affected industries and service sector organizations in short term through the bank system. Half of the interest on the loan is to be paid by the client whereas the rest will be paid by government.

\section{Package-2}

A loan facility of approximately USD 2,353 million, with the interest rate of $9 \%$, is created to provide working Capital Benefits to Small (Cottage Industries) and Medium Enterprises. $4 \%$ loan is to be paid by small and medium enterprises and the remaining $5 \%$ will be paid by the government to the concerned bank.

\section{Package-3}

The current size of the Extending the Benefits of Export Development Fund (EDF), under the Block to Block LC, is declared to be increased from USD 3.5 billion to USD 5 billion in purpose of increasing the import of raw materials. Subsequently, an additional approximately USD 1,500 million will be added to the EDF fund. However, the current interest rate for EDF will be reduced from $2.73 \%$ to $2 \%$.

\section{Package-4}

Bangladesh Bank generates a new loan facility of approximately USD 589 million named Pre-shipment Credit Refinance Scheme with the interest rate of $7 \%$.

\section{Package-5}

An emergency manifesting package has been announced by the government of approximately USD 589 million to pay the salaries / allowances of workers and employees from export oriented industries.

- For agricultural sector, the government of has announced a package titled 'Special Incentive Refinancing Scheme for Agriculture Sector of approximately USD 589 million to provide financial support to the farmers in rural areas.

- Another package of approximately USD 1060 million has been allocated to boost up crop production amidst the pandemic.

- Approximately USD 15 million to rehabilitate the farmers during or after pandemic, while approximately USD 6 million for the farmers already affected by natural inversions and cooperatives agriculture and approximately USD 9 million have been allocated to expand new crops and for technological advancements in agriculture.

- Approximately USD 23.5 million has been allocated to provide with the machineries and seeds among farmers and approximately USD 4.1 million 
has been allocated to buy Aus seeds and fertilizers, while approximately USD 4.25 million for irrigation.

v) 180 combined harvesters and 137 reapers have been allocated to the farmers of the haor regions on emergency basis to alleviate the possible shortage of laborers during the harvesting period of boro crop amidst COVID-19 pandemic. Additionally, the government has determined to distribute nearly 800 combined harvesters and 400 reapers among farmers soon.

vi) Approximately USD 12 million has been allocated by the government to further mechanize or digitalize the agriculture sector.

Besides that, many local companies as well as international financial institutions like World Bank, International Monetary Fund (IMF) etc. are providing emergency funds to strengthen efforts to battle the corona pandemic. Recently, World Bank has approved $\$ 100$ million financing to prevent and respond to the outbreak in Bangladesh.

\section{Lessons to be learnt from COVID-19}

The recent horrifying situation created by COVID-19 pandemic has shaken the whole world with great intensity. This pandemic somehow drastically changed the life of approximately 7 billion earth-dwellers. However, this situation is not different for Bangladesh too. It has halted the way of life people used to have before the outbreak. Industries have almost stoodstill, business and trades are jeopardized because of lockdown. All these incidents are hampering the national and in a word, the world's economy. Yet, COVID-19 has taught us about some amazing as well as momentous facts that previously we were unaware about.

\section{- Practice of Frugality Is Highly Important} In this COVID-19 situation, the thing for which we are going to crave the most is money. We need to learn the art of frugality whether it is about our clothing or foods or daily commodities. Buying unnecessary things should be avoided by hook or by crook. In this situation, spending money to buy luxury of life is nothing but a stupidity as we don't know where is the end of this lockdown! Rather, wealthy people can donate some money for the poor, sick and health workers that are fighting for our lives.

\section{- Biodiversity Can Be Recreated by Changing} People's Lifestyle

Bangladesh was losing its natural beauty day by day because of amplified pollution, mismanagement of tourist spots and so forth. Surprisingly, the disappearing beauty is almost reappearing amidst COVID-19 situation. The credit of this miracle solely goes to lockdown held due to pandemic. Spell bounding scenarios are depicted in the womb of cox bazar sea beaches: dolphins are seen roaming fearlessly, thousands of tiny red crabs are seen washing ashore on beach, deers are seen wandering here and there, turtles are roaming in the saint martin beach and so forth. It's not just about the Cox's bazar, the same thing is applied for Sundarban, Sylhet, Hill side areas, Sanctuary etc. In fact, deforestation has declined at a great rate by refilling the nature with greenery. Plastics are no more polluting the water and diversity of fishes are re-established. Many industries are closed, as a result no more producing smokes to pollute the air of our country. The traffic jam is drastically reduced to almost null in the towns and so the carbon emission. Nature is enjoying its fullest while we are stuck at home. To recapitulate, the nature has got back its beauty giving us a strong and true message that how badly it was treated by us earlier.

\section{- Field of Medicine Should Be Brought Under} Greater Concern

Another lesson we have learnt from the pandemic is how crucial doctors and nurses are for this world to survive. They are working day and night relentlessly to save people by endangering their own lives. So, it is high time we honoured them for their work from now and respect them wholeheartedly. Again, looking at the world's state, one should not think twice to choose medicine as their subject of study. Also, 
funding in biological research should be a matter of concern to be highlighted to save the next decades.

- 'Work from Home' Method Could Be Inaugurated in Workplaces

Lockdown has made it compulsory to close down all the offices. Maximum company and office has started the tradition 'work from home'. If we look at the online banking fact, most of the banks are supporting working from home. Another example is, in the companies like Google, Facebook, YouTube etc their officials don't need to come to office and continue their work from home. Now the head of offices and companies are planning to create virtual offices instead of traditional ones. Subsequently, the companies will no longer need to pay office rent every month of the year and they can smoothly run their business either. People with strong internet connection can work from home and won't need to come to office.

- Online Business Will Get More Popularity development of application for online business such as shopping, food etc. will become available because people in lockdown have become habituated to online shopping (i.e. daraz, alibaba.com) and ordering food online (i.e. foodpanda). So, even after lockdown, there is possibility that online shopping and ordering food will have the same demand and attention as it is getting right now. There is a possibility that entrepreneurship through online food or clothing or selling products can be a source of income for women and men both.

- COVID-19 Will Reduce the Rush of Big Cities and Towns

Internet based jobs or business offered from different office and companies will be made available for people all around the world. People won't need to have physical presence for job as they can work easily from home. In fact, many people will move from city to small towns in order to reduce their daily cost. They will realize that, living and working in traffic free, peaceful village area surrounded by natural beauty is better than staying in expensive apartments of big towns. They may establish a strong WiFi connection for working from their home town.

Furthermore, any international company from any corner of the world can hire people. The term 'globalization' will be broader in sense by the blissful action of internet. Companies can hire any talented people from any place of the world and also that person won't need visa or immigration for working in that company. For example, a person of Bangladesh can work in google company of America if he is having a strong internet connection, laptop, IT skill and degree.

All these events are pointing that the people with computer skill who are annoyed with the noise, pollution and traffic of city may soon be immigrated to small towns for living a happy life with family. Therefore, a huge change will be visible in city after this COVID-19 situation. So, it's clear that we should develop IT skills, freelancing, video editing etc. if we want to lead a decent life when the life will be free from COVID-19.

- Educational System Should Professionally Include Online Classes

Some national and international universities, medical college, school, college and other institutions etc. are arranging online classes to prevent session jam. Most of the Bangladeshi students are not habituated to online classes. But this pandemic has made it mandatory for many of them to continue online classes. However, this procedure may stay long due to lockdown. Even after lockdown, Institutions will continue arranging online classes, courses, sessions etc to ensure proper education for students. Hence, to lead an upgraded life and for better future after COVID-19, we could upgrade our way of regular life. Again, our compassion for relatives, neighbours, friends as 
well as for the whole nation is an obligation to fight the after effects of COVID-19.

The facts mentioned above are however the lessons of COVID-19 for us. This pandemic is going to make huge difference in the upcoming world economy and majority of the people will be afflicted with severe poverty. After this pandemic, the world will be facing a revolutionary change. Not only that, this change will last for a long time. Many of our lives will be fully different. To adapt ourselves with this change, we must modernize our perceptions of traditional lifestyle as well as take some fruitful steps.

\section{Concluding Remark}

COVID-19 has greatly changed the global environment right away as well as revealed some disguised issues that need to be highlighted. According to WHO, Corona virus will never leave this planet, similar situations will cling us ever and anon. To tackle the crisis we are moving forward to, we should get prepared with necessary measures taken. Biomedical research should be widespread and more funded. Health issues are to be paid with much more priority and its high time countries around the world approached concertedly with compassionate international cooperation established.

\section{Acknowledgement}

Authors are thankful to the members of Swift Integrity Computational Lab, Dhaka, Bangladesh, a virtual platform of young researchers, for their supports during the preparation of the manuscript.

\section{Conflict of Interest}

Authors declare that there is no conflict of interest regarding the publication of this manuscript.

\section{Funding Statement}

Authors received no funding from external sources.

\section{Reference}

1. Valencia DN. Brief review on COVID-19: the 2020 pandemic caused by SARS-CoV-2. Cureus. 2020 Mar;12(3).

2. Mbae N. COVID-19 in Kenya. Electron J Gen Med. 2020; 17 (6): em231.

3. Islam H, Rahman A, Masud J, Shweta DS, Araf Y, Ullah MA, Sium SM, Sarkar B. A Generalized Overview of SARS-CoV-2: Where Does the Current Knowledge Stand?. Electron J Gen Med. 2020; 17 (6): em251.

4. Guan WJ, Liang WH, Zhao Y, Liang HR, Chen ZS, Li YM, Liu XQ, Chen RC, Tang CL, Wang T, Ou CQ. Comorbidity and its impact on 1590 patients with Covid-19 in China: A Nationwide Analysis. European Respiratory Journal. 2020 May 1;55(5).

5. Niazkar M, Niazkar HR. COVID-19 Outbreak: Application of Multi-gene Genetic Programming to Country-based Prediction Models. Electron J Gen Med. 2020; 17 (5): em247.

6. Zu ZY, Jiang MD, Xu PP, Chen W, Ni QQ, Lu GM, Zhang LJ. Coronavirus disease 2019 (COVID-19): a perspective from China. Radiology. 2020 Feb 21:200490.

7. Zhou F, Yu T, Du R, Fan G, Liu Y, Liu Z, Xiang J, Wang Y, Song B, Gu X, Guan L. Clinical course and risk factors for mortality of adult inpatients with COVID-19 in Wuhan, China: a retrospective cohort study. The lancet. 2020 Mar 11.

8. Islam MT, Talukder AK, Siddiqui MN, Islam T. Tackling the Pandemic COVID-19: The Bangladesh Perspective.

9. Coronavirus disease 2019 (COVID-19) Situation Report-48, 08 March 2020

10. Coronavirus disease 2019 (COVID-19) Situation Report-58, 18 March 2020

11. Santacroce L, Charitos IA, Del Prete R. COVID-19 in Italy: an overview from the first case to date. Electron J Gen Med. 2020; 17 (6): em235.

12. Jin JM, Bai P, He W, Wu F, Liu XF, Han DM, Liu $\mathrm{S}$, Yang JK. Gender differences in patients with COVID-19: Focus on severity and mortality. Frontiers in Public Health. 2020 Apr 29;8:152 
13. World Health Organization, Bangladesh; COVID19 Situation Report No \# 12, 18 May 2020

14. IEDCR [Internet]. IEDCR. [cited 2020May24]. Available from: https://www.iedcr.gov.bd/

15. Mizumoto K, Kagaya K, Zarebski A, Chowell G. Estimating the asymptomatic proportion of coronavirus disease 2019 (COVID-19) cases on board the Diamond Princess cruise ship,

16. Aljofan M, Gaipov A. COVID-19 Treatment: The Race Against Time. Electron J Gen Med. 2020; 17 (6): em227.
17. Cao YC, Deng QX, Dai SX. Remdesivir for severe acute respiratory syndrome coronavirus 2 causing COVID-19: An evaluation of the evidence. Travel Medicine and Infectious Disease. 2020 Apr 2:101647. 
